\title{
Remaining Recoverable Petroleum in Ten Giant Oil Fields of the Los Angeles Basin, Southern California
}

Tsing a probabilistic geology-
based methodology, a team of
U.S. Geological Survey (USGS)
scientists recently assessed the
remaining recoverable oil in
10 oil fields of the Los Angeles
Basin in southern California. The
results of the assessment suggest
that between 1.4 and 5.6 billion
barrels of additional oil could be
recovered from those fields with
existing technology.

The Los Angeles Basin is a deep structural feature that began forming near the margin of the North American and Pacific Plates about 7 million years ago, during Late Miocene time (Wright 1991). The basin is bounded on the northwest by the Santa Monica Mountains, on the southeast by the San Joaquin Hills, on the east by the Puente Hills, and on the west by the Palos Verdes Peninsula. The basin's small areal extent, prolific source rocks, thick sandstone reservoirs, and large anticlinal traps constitute a nearly ideal petroleum system. As a result, the Los Angeles Basin has one of the highest concentrations of crude oil in the world. Sixty-eight oil fields have been named in an area of about 450 square miles, including 10 accumulations that each contain more than 1 billion barrels of oil. One of these, Wilmington-Belmont, is the fourth largest oil field in the United States.

Development of the oil fields during the twentieth century went hand in hand with rapid population growth and extensive urbanization of the Los Angeles Basin. Competing land use practices and evolving community priorities have constrained petroleum development throughout the history of the basin. In spite of abundant in-place resources and famously high local demand for refined petroleum products, recovery efficiency remains low and basinwide production continues to fall. Many small to medium-size oil fields have already been shut-in or abandoned, and recovery of oil

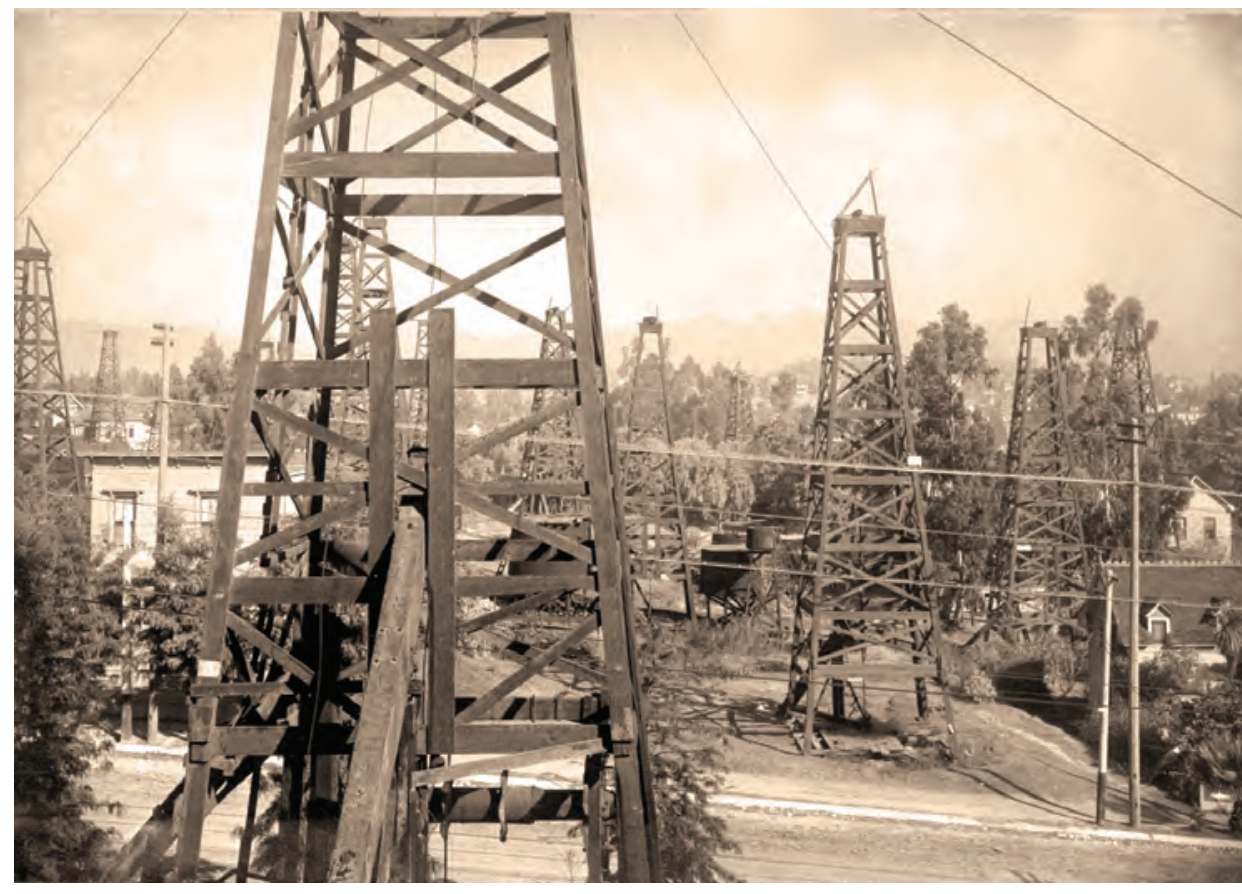

Oil derricks and houses in central Los Angeles, 1905. USGS photo by Ralph Arnold.

from larger fields is increasingly restricted by State, County, and local policies and by competing commercial interests.

A team of U.S. Geological Survey (USGS) scientists has assessed the remaining recoverable oil in the 10 giant oil fields in the Los Angeles Basin using a probabilistic geology-based methodology (Klett and others, 2011) and reserves and production data from the California Division of Oil, Gas, and Geothermal Resources (2007). The team analyzed the geology of each field and reviewed its engineeringdevelopment history. Probability distributions for original oil in place (OOIP) were estimated for each field, and the fraction of the OOIP already developed was calculated. The probable range of maximum potential recovery efficiency $\left(\mathrm{RE}_{\max }\right)$ was evaluated on the basis of recovery efficiencies that have been modeled in engineering studies, achieved in similar reservoirs elsewhere, or indicated by laboratory results reported in technical literature. Probability distributions of OOIP and $\mathrm{RE}_{\max }$ were combined in a Monte Carlo simulation to estimate remaining recoverable oil.

On the basis of this assessment of remaining oil in place and potential recovery efficiency, between 1.4 and 5.6 billion barrels of additional recoverable oil are estimated to remain in the 10 analyzed fields, with a mean estimate of approximately 3.2 billion barrels. Substantial recovery of these resources would require field redevelopment and unrestricted application of current bestpractice technology, including improved imaging and widespread application of directional drilling, combined with extensive water, steam, and $\mathrm{CO}_{2}$ floods.

Beyond the resources in the fields assessed here, additional recoverable oil may also remain in the other 58 existing oil fields in the Los Angeles Basin, in yet-to-find conventional oil fields, and in unconventional resources in petroleum source rocks (shale oil). Given the highly urbanized condition of the Los Angeles Basin, unrestricted development is hard to envision. Nevertheless, significant petroleum resources could probably be developed if needed. 


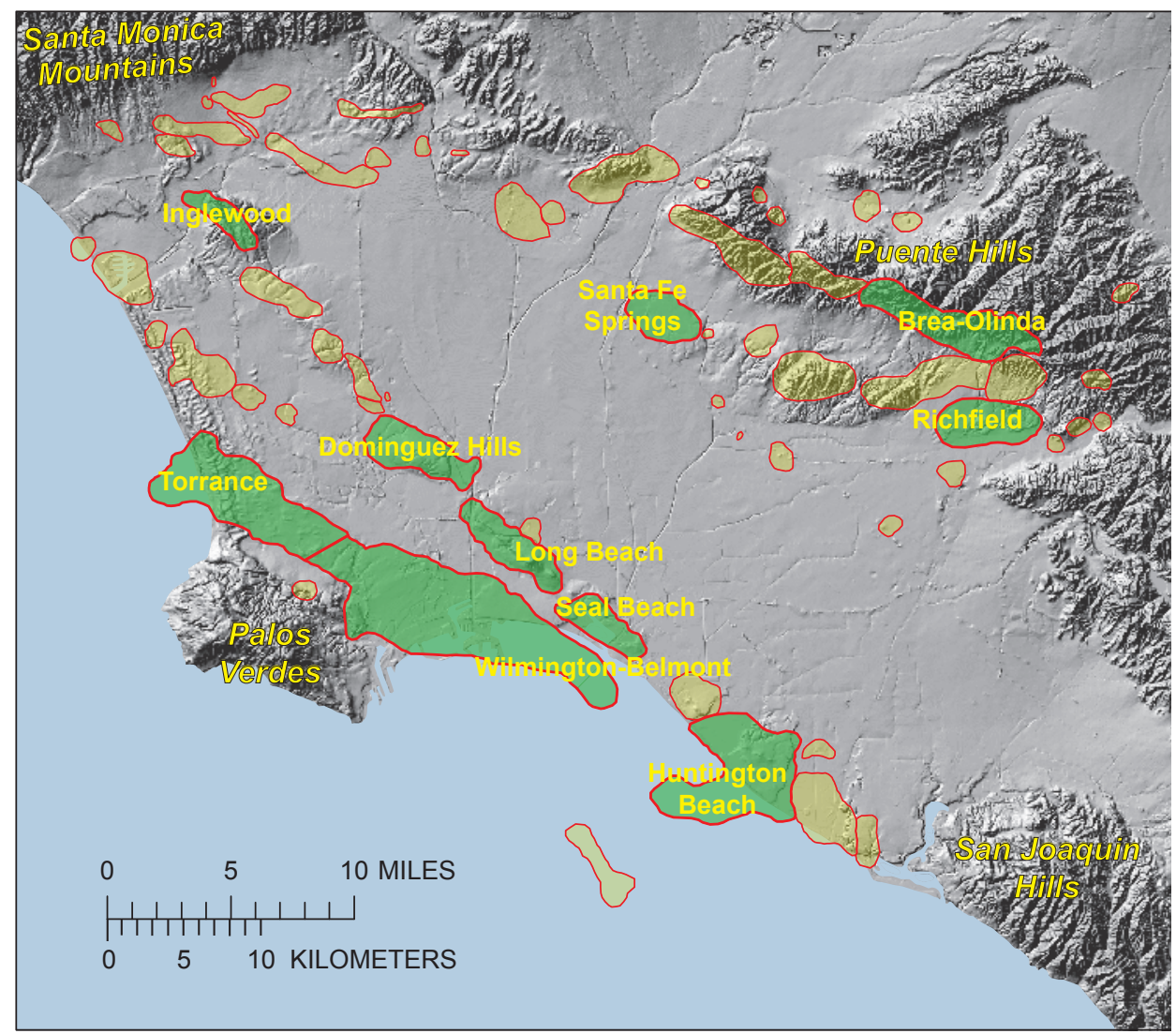

Map of the Los Angeles Basin, showing oil fields (outlined in red). Fields evaluated in this study are shaded green and labeled by name.

Table 1. Assessment results for volumes of remaining recoverable oil in selected oil fields of the Los Angeles Basin, California (technically recoverable resources).

\section{References Cited}

California Division of Oil, Gas, and Geothermal Resources, 2007, 2006 annual report of the State Oil and Gas Supervisor: California Department of Conservation, Division of Oil, Gas, and Geothermal Resources, publication no. PR-06, 276 p., accessed April 2, 2012, at http://www. conservation.ca.gov/dog/pubs_stats/annual_ reports/Pages/annual_reports.aspx.

Klett, T.R., Attanasi, E.D., Charpentier, R.R., Cook, T.A., Freeman, P.S., Gautier, D.L., Le, P.A., Ryder, R.T., Schenk, C.J., Tennyson, M.E., and Verma, M.K., 2011, New U.S. Geological Survey method for the assessment of reserve growth: U.S. Geological Survey Scientific Investigations Report 2011-5163, 8 p., available at http://pubs.usgs.gov/sir/2011/5163/.

Wright, T.L., 1991, Structural geology and tectonic evolution of the Los Angeles Basin, California, in Biddle, K.T., ed., Active margin basins: American Association of Petroleum Geologists Memoir 52, p. 35-103.

Reserve Growth Assessment Team: Donald L. Gautier, Marilyn E. Tennyson, Troy A. Cook, Ronald R. Charpentier, and Timothy R. Klett

Edited by Peter H. Stauffer Graphic design by Judy Weathers

For more information, visit:

USGS Energy Resources Program Web site, http://energy.usgs.gov/ or contact:

Donald L Gautier (gautier@usgs.gov) 345 Middlefield Road

Menlo Park, California 94025

This Fact Sheet and any updates to it are available online at http://pubs.usgs.gov/fs/2012/3120/

[Known recoverable oil is the sum of cumulative production and reported remaining reserves; mean estimates add to a total mean, but fractile values for individual fields are not additive; fractiles (nonadditive) for the entire group of fields are shown in the bottom row, highlighted in yellow. OOIP, original oil in place; MMBO, million barrels of oil. F95 denotes a 95-percent chance of at least the amount tabulated; F50 denotes a 50-percent chance; F05 denotes a 5-percent chance]

\begin{tabular}{|c|c|c|c|c|c|c|c|c|c|c|c|}
\hline \multirow[t]{2}{*}{ Field } & \multirow{2}{*}{$\begin{array}{l}\text { Known } \\
\text { recoverable } \\
\text { oil (MMBO) }\end{array}$} & \multicolumn{3}{|c|}{ Estimated 00IP (MMBO) } & \multicolumn{3}{|c|}{$\begin{array}{c}\text { Estimated recovery efficiency } \\
\text { (percent) }\end{array}$} & \multicolumn{4}{|c|}{ Remaining recoverable oil (MMBO) } \\
\hline & & Minimum & Median & Maximum & Minimum & Mode & Maximum & F95 & F50 & F05 & Mean \\
\hline Brea-Olinda & 431 & 1,200 & 1,600 & 2,400 & 35 & 40 & 45 & 81 & 209 & 407.6 & 221.9 \\
\hline Dominguez Hills & 274 & 1,000 & 1,200 & 1,450 & 35 & 40 & 50 & 146 & 224 & 321.2 & 227.7 \\
\hline Huntington Beach & 1,164 & 3,250 & 3,500 & 6,000 & 35 & 40 & 55 & 117.1 & 371.5 & 866.2 & 416.2 \\
\hline Inglewood & 430 & 1,000 & 1,400 & 2,500 & 40 & 45 & 55 & 67.2 & 224.6 & 520.2 & 249.9 \\
\hline Long Beach & 946 & 3,000 & 3,100 & 3,600 & 35 & 40 & 55 & 207.9 & 392.2 & 663.5 & 410.3 \\
\hline Richfield & 206 & 800 & 1,000 & 2,400 & 26 & 30 & 45 & 48.2 & 134.5 & 356.5 & 158.7 \\
\hline Santa Fe Springs & 634 & 2,100 & 2,378 & 2,700 & 30 & 35 & 40 & 96.7 & 197.5 & 308 & 199.6 \\
\hline Seal Beach & 221 & 850 & 900 & 1,000 & 35 & 40 & 50 & 109.4 & 152.9 & 210 & 155.7 \\
\hline Torrance & 232 & 900 & 1,000 & 2,000 & 35 & 40 & 55 & 127.8 & 207.7 & 394.3 & 226.7 \\
\hline Wilmington-Belmont & 2,984 & 7,600 & 9,000 & 12,000 & 35 & 40 & 55 & 199.9 & 909.8 & $1,948.1$ & 972.6 \\
\hline All evaluated fields & 7,522 & & & & & & & 1,443 & 3,079 & 5,565 & 3,239 \\
\hline
\end{tabular}

